\title{
Platelet abnormalities and platelet-to-lymphocyte ratios in canine immunosuppressant-responsive and non-responsive enteropathy: A retrospective study in 41 dogs
}

\author{
Alessio PIERINI ${ }^{1)}$, Giada ESPOSITO ${ }^{1)}$, Eleonora GORI ${ }^{1) *}$, Elena BENVENUTI'), \\ Pietro RUGGIERO' ${ }^{2)}$, George LUBAS $^{1)}$ and Veronica MARCHETTI ${ }^{1)}$ \\ 1)Department of Veterinary Science, University of Pisa, Via Livornese Lato Monte, 56122 Pisa, Italy
2) Private Professional Association Endovet, Via Antonio Oroboni, 8-00149 Roma, Italy
}

J. Vet. Med. Sci.

83(2): 248-253, 2021

doi: 10.1292/jvms.20-0291

\section{Received: 16 May 2020}

Accepted: 23 November 2020 Advanced Epub:

15 January 2021
ABSTRACT. Few studies have examined platelet alterations in dogs with chronic enteropathy. Our aim was to investigate platelet count (PLT), mean platelet volume (MPV), and platelet-tolymphocyte ratio (PLR) in dogs diagnosed with immunosuppressant-responsive enteropathy (IRE). In this retrospective study of 41 dogs, data regarding signalment, canine chronic enteropathy clinical activity index (CCECAI), endoscopic and histopathological scores, PLT, MPV, PLR, total serum protein concentrations, albumin, and iron were collected. Clinical response and relapse were assessed with the evaluation of CCECAI over time. One month after starting therapy, dogs with $>25 \%$ CCECAI reduction were considered responders. During a three-month CCECAI evaluation as part of a twelve-month follow-up, a CCECAI $>3$ together with a $\geq 2$ unit increase in responder dogs was considered a relapse. PLT and PLR displayed significant negative correlation with MPV. MPV was positively correlated with total protein and albumin levels and negatively correlated with CCECAI. Three dogs were classified as non-responders, and 14 relapsed within 12 months. No differences were observed in PLT, MPV, or PLR between responding/non-responding and relapsing/non-relapsing groups. PLT, MPV, and PLR correlated with total protein, albumin, and CCECAI, confirming PLT as a potential marker, and suggesting MPV as a new marker of clinical efficacy against canine IRE.

KEY WORDS: canine, chronic, complete blood count, lymphopenia, thrombocytosis

Chronic enteropathies (CE) are frequently occurring intestinal diseases in dogs, and are characterized by clinical signs such as vomiting, diarrhea, borborygmus, abdominal pain, nausea, and/or weight loss for more than 3 weeks. Chronic enteropathies can be divided retrospectively based on their response to treatment into food-responsive enteropathies, antibiotic-responsive enteropathies, immunosuppressant-responsive enteropathies (IREs), and non-responsive enteropathies (NREs) [8]. The term inflammatory bowel disease (IBD), which includes IREs and NREs, implies that trial diet and antibiotic treatments have failed to resolve clinical signs, and histology demonstrates intestinal inflammation [8]. The canine chronic enteropathy clinical activity index (CCECAI) and the canine IBD activity index (CIBDAI) are two different proposed methods of diagnosing and monitoring disease activity in dogs with CE $[3,15]$.

A complete blood count (CBC) is currently included in the diagnostic work-up of dogs diagnosed with CE. A CBC offers a quick evaluation of quantitative and qualitative alterations in erythrocytes, leukocytes, and platelets. With CBC parameters, it is possible to calculate ratios between different types of cells (e.g., neutrophils, lymphocytes, and platelets) [9, 27]. In human medicine, the CBC of patients with IBD has been widely studied. People diagnosed with ulcerative colitis and Crohn's disease are considered at high risk of systemic thrombotic events [36]. Platelet alterations described in these conditions define the condition "reactive thrombocytosis". Reactive thrombocytosis is characterized by changes in platelet shape and number, increased platelet activation, increased adhesiveness to the vascular endothelium, and a tendency to form homotypic (platelet-platelet) and heterotypic (platelet-leukocyte) aggregates [36]. In addition, mean platelet volume (MPV) decreases as a result of thrombopoiesis abnormalities, and platelet consumption increases during the inflammatory process [36]. Moreover, iron deficiency is reported to be 
associated with reactive thrombocytosis in dogs, together with chronic inflammation, occult chronic gastrointestinal bleeding, and inadequate iron intake with food, reducing iron availability in dogs diagnosed with CE [26].

In veterinary medicine, few studies have been conducted on platelet alterations in dogs with CE. Ridgway et al. (2001) focused on the association between thrombocytopenia and CE, and reported a 2.5\% incidence of thrombocytopenia in dogs with CE [32]. In two other studies, thrombocytopenia and thrombocytosis were found in $0-13 \%$ and $6-32 \%$ of cases, respectively [7, 24]. The frequency of thrombocytosis decreased from 32 to $23 \%$ when evaluated after immunosuppressant treatment [24]. More recently, platelet count (PLT) has been positively correlated with CCECAI in twenty-two dogs diagnosed with CE [27].

Platelet-to-lymphocyte ratio (PLR) can easily be extrapolated from CBC. PLR seems to better predict clinical outcomes in patients with systemic inflammation than either platelet or lymphocyte count alone [10]. Briefly, stress-induced hypercortisolemia with subsequent platelet release into the peripheral blood, and transient lymphopenia may influence the degree of PLR elevation. In human medicine, PLR is considered to be a novel inflammation marker, which has been linked to adverse outcomes in various cardiovascular and neoplastic diseases [21, 22]. Information from investigations of PLR in people diagnosed with CE is limited to a few studies with disparate results $[2,5,9]$. To the best of the authors' knowledge, only one study has investigated the role of PLR in dogs affected by different canine oral diseases with no association among them [31].

We hypothesized that PLT and PLR may positively correlate with disease severity, and that MPV may negatively correlate. Moreover, PLT, MPV, and PLR can be associated with previously identified prognostic markers in enteropathic patients [3, 8, $11,13,28]$. Thus, they may be useful as novel biomarkers of IRE severity in dogs. The first aim of this study was to investigate relationships between PLT, MPV, PLR, serum concentrations of total protein, albumin, and serum iron, and CCECAI in dogs with IRE and NRE at the time of diagnosis. The second aim was to compare PLT, MPV, and PLR at time of diagnosis between the two groups, and assess correlation with clinical response to immunomodulatory treatment.

\section{MATERIALS AND METHODS}

Medical records of two referral hospitals were searched for dogs affected by IRE and NRE between January 2018 and January 2019. IRE was suspected after ruling out extra-intestinal diseases, infectious or parasitic diseases, and intestinal disease of other etiologies (e.g., mechanical obstruction from intussusception, foreign body, or intestinal tumors). Dogs were included in the IRE group after exclusion of food-responsive enteropathy (responding to a hydrolyzed diet or a novel antigen diet) and exclusion of antibiotic responsive enteropathy (responding to treatment with $10 \mathrm{mg} / \mathrm{kg} / 12 \mathrm{hr}$ tylosin for at least 2 weeks) [8]. A diagnosis of chronic inflammatory enteropathy was based on compatible endoscopic and histopathological examinations. For each dog included in the study, immunomodulatory therapy was provided using prednisolone (from 0.5 to $1 \mathrm{mg} / \mathrm{kg}$ every $12 \mathrm{hr}$ ) with or without cyclosporine $(5 \mathrm{mg} / \mathrm{kg}$ every $24 \mathrm{hr}$ ) at the discretion of the clinician. No dogs received immunomodulatory drugs prior to inclusion. A final diagnosis of IRE or NRE was based on response to immunomodulatory treatment. The first day of immunomodulation therapy was designated T0. The CCECAI score was collected for each dog on the same day as their endoscopic evaluation [3]. Both endoscopic and histologic scores of the duodenum were assigned using a severity score ranging from 0 to 3 , according to a previously published scoring system [37]. CCECAI scores were recalculated for each dog at one (T1), 3 (T3), 6 (T6), and 12 (T12) months after initiation of immunosuppressant therapy during clinical checkups. If a dog died due to IRE/NRE progression or relapse between two consecutive time points (e.g., between T3 and T6), they were considered dead or relapsed at the longer time point. Dogs that died due to IRE/NRE-unrelated causes were removed from statistical analyses.

Based on CCECAI at T1, dogs were divided into responder and non-responder groups [13]. Dogs with a reduction in CCECAI of $>25 \%$ at T1were classified as responders, whereas dogs with $\leq 25 \%$ reduction in CCECAI at T1 were classified as nonresponders and diagnosed with NRE. The relapse rate was evaluated over 12 months. If CCECAI at T3, T6, and T12 was $\leq 3$, the dog was considered in remission. If CCECAI was $>3$, differences $(\Delta)$ between CCECAI at T3, T6, and T12 and the previous closest time point were calculated to obtain $\Delta$-CCECAI T3-T1, T6-T3, and T12-T6. A $\Delta$-CCECAI $\geq 2$ was considered a relapse. Depending on which time point was assessed, deceased dogs were assigned to the non-responsive (T0-T1) or relapsed groups.

For all dogs, a complete blood count (Procyte DX, IDEXX Laboratories, Westbrook, ME, USA), including a blood smear evaluated by experienced clinical pathologists, was performed within an hour after blood sample collection, and within a week before endoscopy. Absolute lymphocyte number and PLT, obtained from the blood count analyzer and confirmed by the clinical pathologist, and MPV values were collected for each dog. PLR was calculated as the ratio of the absolute values of platelets and lymphocytes. Dogs were divided into two groups based on in-house laboratory reference range of MPV (decreased, MPV $<8.7$ $\mathrm{fl}$; normal/increased $\geq 8.7 \mathrm{fl}$ ). Serum total protein, albumin, and iron values, obtained using an automated biochemistry analyzer (Liasys, Assel SRL, Rome, Italy), were also collected at the same time point.

Continuous and ordinal variables are presented as medians with interquartile range (IQR). Categorical data were presented as absolute and relative frequencies. All continuous variables (PLT, MPV, PLR, total protein, albumin, and iron) were analyzed with the D'Agostino-Pearson test for normal distribution. T0 CCECAI was considered an ordinal variable. Pairwise comparisons of continuous and ordinal variables were performed using Pearson's or Spearman's correlation tests. Correlation was considered mild, moderate, or strong with $r<0.3$, between 0.3 and 0.6 , or $>0.6$, respectively [1]. Continuous and ordinal parameters were also compared between groups (based on MPV, endoscopic score, histopathological score, response, and relapse) by unpaired $t$-test (parametric data) or Mann-Whitney $U$-test (non-parametric and ordinal data) when two groups were considered (MPV, response, relapse) and one-way ANOVA (for parametric data) or Kruskal-Wallis test (for non-parametric and ordinal data) when three groups were considered (endoscopic score, histopathological score). All statistical analyses were performed using commercial software 
(IBM SPSS Statistics, version 25, IBM Corp., New York, NY, USA). A $P$-value $<0.05$ was considered significant.

\section{RESULTS}

\section{Case selection}

Forty-one dogs with IRE/NRE were retrospectively included. The study population was composed of 27 males (65.8\%), 2 of which were neutered, and 14 females (34.2\%), 6 of which were spayed. Median age was 4 years (range, $1-15$ years). Twenty-nine purebreeds and 12 mixed-breed dogs were included. The most commonly affected breeds were German shepherds ( $\mathrm{n}=7$ ), Boxers $(\mathrm{n}=2)$, Dachshunds $(\mathrm{n}=2)$, Rottweilers $(\mathrm{n}=2)$, and Jack Russel Terriers $(\mathrm{n}=2)$.

\section{Relationships of PLT, MPV, and PLR with clinical and clinicopathological features}

Median PLT was $267 \mathrm{~K} / \mu 1$ (IQR $246 \mathrm{~K} / \mu \mathrm{l})$, and median MPV was $10.0 \mathrm{fl}$ (IQR $2 \mathrm{fl})$. Seven of 41 dogs (17\%) displayed decreased MPV (median, 7.8; IQR, 0.85 fl). Median PLR was 143 (IQR, 196.6). Median CCECAI was 6 (IQR 3). Median total protein was $5.7 \mathrm{~g} / \mathrm{dl}$ (IQR $2.2 \mathrm{~g} / \mathrm{dl}$ ). Median albumin was $2.7 \mathrm{~g} / \mathrm{dl}$ (IQR $1.5 \mathrm{~g} / \mathrm{dl}$ ). Median iron was $150 \mu \mathrm{g} / \mathrm{dl}$ (IQR $85 \mu \mathrm{g} / \mathrm{dl}$ ). Endoscopic score was 2 in 15/41 dogs (37\%), and 3 in 26/41 dogs (63\%). Histological score was 1 in 4/41 dogs (10\%), 2 in 24/41 dogs $(58 \%)$, and 3 in $13 / 41$ dogs $(32 \%)$.

PLT correlated significantly with MPV $(P=0.001, \mathrm{r}=-0.50)$. PLT also significantly correlated with PLR, total protein, albumin, and CCECAI $(P<0.0001, \mathrm{r}=0.87 ; P=0.0008, \mathrm{r}=-0.51 ; P=0.0026, \mathrm{r}=-0.47 ; P=0.0017, \mathrm{r}=0.47$ [Fig. 1A], respectively).

MPV correlated with PLR, total protein, albumin, and CCECAI $(P=0.0034, \mathrm{r}=-0.45 ; P=0.0062, \mathrm{r}=0.44 ; P=0.0080, \mathrm{r}=0.42$; $P=0.0299, \mathrm{r}=-0.34$ [Fig. 1B], respectively) (Table 1). CCECAI was also higher in the decreased MPV group (median CCECAI 6 vs $10, P=0.0009)$. No difference was found between PLT or MPV and endoscopic score groups, or between PLT or MPV and histological score groups.

In addition to PLT and MPV (see above), PLR also significantly correlated with total protein, albumin, and CCECAI ( $P=0.0152$, $\mathrm{r}=-0.39 ; P=0.0297, \mathrm{r}=-0.35$ and $P=0.0368, \mathrm{r}=0.33$ [Fig. 1C], respectively). No difference was found between PLR and endoscopic score groups, or between PLR and histological score groups.

\section{Relationships between PLT, MPV, and PLR, and response to treatment}

At the completion of this study (T12), complete follow-up information was available for thirty-six dogs. Among the five dogs with no long-term follow-up data, T3 was the last checkup for 3 cases, and T6 was the last checkup for 2 cases. Among the thirty-

PLT - CCECAI

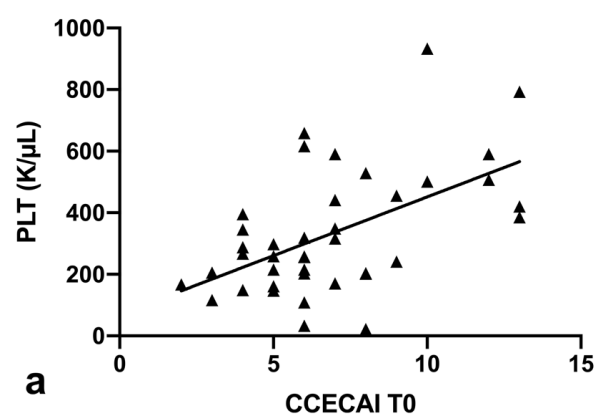

MPV - CCECAI

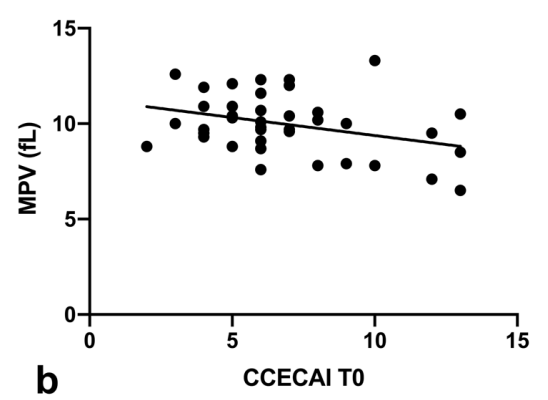

PLR - CECCAI

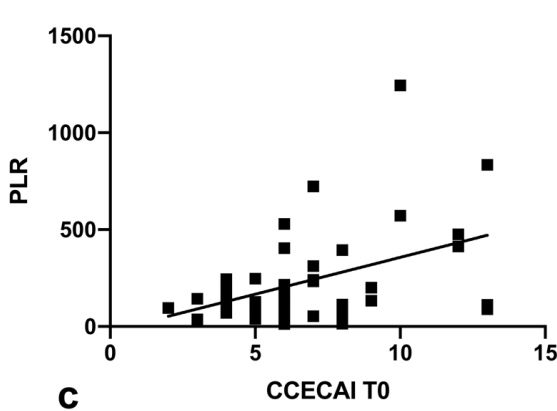

Fig. 1. Correlations between canine chronic enteropathy clinical activity index (CCECAI) and platelet count (PLT) (a; $P=0.0017, \mathrm{r}=0.47)$, mean platelet volume (MPV) $(\mathrm{b} ; P=0.0299, \mathrm{r}=-0.34)$ and platelet-to-lymphocyte ratio (PLR) $(\mathrm{c} ; P=0.0368, \mathrm{r}=0.33)$.

Table 1. Matrix of correlations for continuous variables

\begin{tabular}{|c|c|c|c|c|c|c|}
\hline Variables & $\mathrm{PLT}^{\mathrm{a})}$ & $\mathrm{MPV}^{\mathrm{b})}$ & PLR $^{\text {a) }}$ & Total protein ${ }^{\text {b) }}$ & Albumina) & Iron $^{\text {b) }}$ \\
\hline CCECAI $^{\mathrm{b})}$ & 0.47 & -0.34 & 0.33 & - & - & -0.04 \\
\hline Iron $^{b)}$ & 0.05 & -0.16 & -0.12 & -0.10 & 0.07 & 1 \\
\hline Albumin ${ }^{a}$ ) & -0.47 & 0.42 & -0.35 & 0.88 & 1 & \\
\hline Total protein ${ }^{\mathrm{b})}$ & -0.51 & 0.44 & -0.39 & 1 & & \\
\hline $\operatorname{PLR}^{\mathrm{a})}$ & 0.87 & -0.45 & 1 & & & \\
\hline$M V^{b)}$ & -0.50 & 1 & & & & \\
\hline
\end{tabular}

a) Non-parametric; b)parametric. Spearman's correlation was used to the pairwise comparisons between variables if at least one variable showed a non-parametric distribution. Pearson's correlation was used if both the two variables showed a normal distribution. Bold characters: $P<0.05$. See the text for more details regarding $P$-values. CCECAI, canine chronic enteropathy clinical activity index; PLT, platelet count, MPV, mean platelet volume, PLR, platelet-to-lymphocyte ratio. 
Table 2. Comparisons between platelet count (PLT), mean platelet volume (MPV) and platelet-to-lymphocyte ratio (PLR) and the groups based on clinical response and clinical relapse

\begin{tabular}{|c|c|c|c|c|c|c|c|}
\hline & & $\operatorname{PLT}(\mathrm{K} / \mu \mathrm{l})$ & $P$-value & MPV (fl) & $P$-value & PLR & $P$-value \\
\hline T1 Response & $\begin{array}{c}\text { Yes } \\
(\mathrm{n}=33) \\
\text { No } \\
(\mathrm{n}=3)\end{array}$ & $\begin{array}{c}259 \\
(\text { IQR } 280) \\
501 \\
(385-933)\end{array}$ & 0.08 & $\begin{array}{c}10.1 \\
\text { (IQR 1.8) } \\
8.5 \\
(7.8-13.3)\end{array}$ & 0.68 & $\begin{array}{c}132 \\
(\mathrm{IQR} 206) \\
571 \\
(111-1,244)\end{array}$ & 0.13 \\
\hline T3 Relapse & $\begin{array}{c}\text { Yes } \\
(\mathrm{n}=6) \\
\text { No } \\
(\mathrm{n}=27)\end{array}$ & $\begin{array}{c}428 \\
\text { (IQR 566) } \\
259 \\
\text { (IQR 250) }\end{array}$ & 0.48 & $\begin{array}{c}10.0 \\
\text { (IQR 3.2) } \\
10.2 \\
\text { (IQR 2.3) }\end{array}$ & 0.18 & $\begin{array}{c}303 \\
\text { (IQR 572) } \\
129 \\
\text { (IQR 169) }\end{array}$ & 0.51 \\
\hline T6 Relapse & $\begin{array}{c}\text { Yes } \\
(\mathrm{n}=6) \\
\text { No } \\
(\mathrm{n}=21)\end{array}$ & $\begin{array}{c}278 \\
\text { (IQR 297) } \\
259 \\
\text { (IQR 239) }\end{array}$ & 0.76 & $\begin{array}{c}10.3 \\
\text { (IQR 3.3) } \\
10.2 \\
\text { (IQR 2.1) }\end{array}$ & 0.55 & $\begin{array}{c}171 \\
\text { (IQR 455) } \\
129 \\
\text { (IQR 169) }\end{array}$ & 0.48 \\
\hline T12 Relapse & $\begin{array}{c}\text { Yes } \\
(\mathrm{n}=2) \\
\text { No } \\
(\mathrm{n}=19)\end{array}$ & $\begin{array}{c}492 \\
(395-590) \\
257 \\
\text { (IQR 182) }\end{array}$ & 0.09 & $\begin{array}{c}9.9 \\
(9.3-10.4) \\
10.2 \\
(\text { IQR 2.5) }\end{array}$ & 0.69 & $\begin{array}{c}261 \\
(209-312) \\
113 \\
(\text { IQR 170) }\end{array}$ & 0.24 \\
\hline
\end{tabular}

IQR, interquartile range. IQR for T1 non-responders and for T12 relapsed dogs were not calculated due to the low number of subjects, thus the range (IQR or min-max) was reported. All comparisons were tested with the unpaired Mann-Whitney $U$-test.

six dogs, 8 died due to progression of IRE/NRE, and 28 survived the full study period. The eight deceased dogs died within the first six months. Two dogs were deceased by T1, three were deceased by T3, and three were deceased by T6. Seventeen (47.2\%) of 36 dogs were considered non-responders, or showed relapsing disease within T12. Based on CCECAI scores, three dogs were diagnosed with NRE at T1, six dogs relapsed at T3, six dogs relapsed at T6, and two dogs relapsed at T12. No statistical differences were observed in PLT, MPV, and PLR between responder/non-responder and relapsing/non-relapsing at any time point (Table 2).

\section{DISCUSSION}

In human medicine, platelet alterations are well-known extra-intestinal IBD manifestations, affecting patients' clinical outcomes $[30,33]$. In veterinary medicine, platelet alterations have been poorly studied in dogs with chronic enteropathies. The results of this preliminary study suggest that some platelet parameters could be useful tools for therapeutic and prognostic purposes in dogs diagnosed with IRE [24, 27].

In the present study, PLT correlated negatively with total serum protein and albumin levels. This negative correlation between PLT and serum albumin may reflect a hypercoagulable state [12]. A study of 15 dogs with protein-loss associated enteropathies showed that all were hypercoagulable compared to healthy dogs [12]. The pathogenesis of this phenomenon is unknown. However, some evidence suggests that albumin loss is associated with loss of antithrombin $[6,14,35]$. Increased PLT and hypercoagulable status may therefore both be due to antithrombin loss and increased release of inflammatory mediators.

In our study, PLT correlated positively with CCECAI score at T0. Since the magnitudes of decrease in serum total protein and albumin, and increase in CCECAI score were positively associated with severity of enteropathy [3, 16], PLT would likely tend to increase as a consequence of increased inflammatory cytokine release [36]. In support of this theory, aberrant thrombopoiesis caused by inflammatory mediators, and accelerated platelet activation and consumption at the inflammation site, have been suggested to reduce platelet lifespan, consequently increasing PLT in human IBD patients [36]. As shown in Table 1, in the present study, lack of correlation between serum iron and PLTs suggests a hypothesis of reactive thrombocytosis due to hyposideremia.

Moreover, MPV correlated positively with albumin and total serum protein, and correlated negatively with PLT, PLR, and CCECAI scores at T0. In human medicine, MPV alterations correlate with inflammatory disease and cancer [19, 20]. Moreover, MPV correlates negatively with duration of intestinal inflammation, endoscopic index, and clinical activity score in people with IBD [17, 25, 29, 39]. Furthermore, MPV was able to distinguish healthy people from people with Crohn's disease and those with inactive ulcerative colitis $[4,23,39]$. As seen above, thrombopoiesis abnormalities, increased platelet consumption, and release of immature, smaller platelets from the bone marrow to the peripheral blood can occur [36]. In the present study, MPV correlated with some known negative prognostic factors (i.e., total protein, albumin, and CCECAI) in dogs with IRE, highlighting the role of MPV as an easy, inexpensive prognostic marker in canine IRE. Smaller platelets and reactive thrombocytosis due to increased MPV and normalization of PLT values after iron replacement therapy in people affected with iron deficiency anemia appeared to be associated with iron deficiency due to lack of suppression of iron-mediated megakaryopoiesis [18, 38]. However, lack of correlation between serum iron and MPV makes the hypothesis of decreased MPV due to iron deficiency less likely.

One purpose of the present study was to investigate PLR in dogs with IRE. PLR has been associated with prognosis in several 
human diseases $[21,22]$. In the present study, the strong correlation observed between PLT and PLR, and the similar levels of significance observed in correlation test analyses with other variables suggest that PLR may not increase diagnostic efficacy over PLT alone.

The last aim of the present study was to evaluate the prognostic roles of PLT, MPV, and PLR. Dogs with a CCECAI reduction of $>25 \%$ during the first month of therapy were considered responders, as previously reported [13, 28]. However, we used a novel criterion to classify relapse in dogs. We decided that CCECAI $<3$ should be considered clinically insignificant, even if it had increased relative to the most recently calculated CCECAI. For CCECAI $>3$, we decided to use changes in score units $(\geq 2)$ and did not change score percentages. In fact, since the minimum possible increase in CCECAI score is one unit, the increase in percentage would be too different between an increase in CCECAI score from 4 to $5(25 \%)$ compared to an increase in CCECAI score from 8 to $9(12.5 \%)$. Finally, we considered a single unit increase insignificant, and an increase in CCECAI of at least 2 units more consistent with relapse. Even with these criteria, the present study failed to find an association between response or relapse and PLT, MPV, and PLR.

This study has some limitations. Due to its retrospective nature, the present study did not rule out possible confounding factors (e.g., medications and dosages). In addition, since other specific platelet functional tests (e.g., buccal mucosal bleeding time and thromboelastography) were not tested, the presence of functional platelet disorders cannot be ruled out. The presence of other subclinical or unrecognized inflammatory diseases (e.g., periodontitis [31]) could also have influenced our findings. However, almost all dogs were young adults, making this scenario unlikely. Although blood samples are routinely carried out in-house within $1 \mathrm{hr}$, we were not able to rule out pseudo-thrombocytopenia due to the addition of EDTA to collected blood samples. Pseudothrombocytopenia is a well-known phenomenon in humans, and is related to EDTA-induced alteration of surface glycoproteins and anionic phospholipids, enabling the binding of antiplatelet antibodies, which in turn causes agglutination [34]. In the present study, all blood smear evaluations agreed with instrumental findings (data not shown), making pseudo-thrombocytopenia less likely. Although PLR did not show any advantages in comparison with PLT, we did not evaluate the relationship between PLR and the presence of lymphangiectasia. In fact, lymphocytopenia that can occur in dogs diagnosed with lymphangiectasia may increase PLR values. Thus, the relationship between these two variables would be interesting to evaluate. Lastly, we decided to use CCECAI as a marker for response and relapse. If the CCECAI score at T0 was 9 and dropped to 0 , treatment was obviously effective. This is not necessarily the case when a CCECCAI of 14 at T0 drops to 6 . To date, no consensus on how to consider a treatment appropriate, and how to manage relapses is available. For this reason, we cannot rule out flawed criterion in identifying response and relapse in dogs.

The present study reported that PLT, MPV, and PLR collected at case presentation time correlated with serum total protein, albumin, and CCECAI, thus supporting the previously stated hypothesis that PLT could be a marker of clinical activity of chronic enteropathy in dogs [27]. The present study proposes MPV as a new marker for IRE in dogs. Baseline PLT, MPV, and PLR were not associated with endoscopic and histopathological scores, and seemed unhelpful in predicting response to therapy or relapse of the disease. However, increasing the study population, monitoring changes in PLT, MPV, and PLR over time and evaluating specific histomorphological alterations (i.e., lacteal dilation) rather than histopathological scores would be necessary to confirm our findings.

POTENTIAL CONFLICTS OF INTEREST. The authors have nothing to disclose.

\section{REFERENCES}

1. Akoglu, H. 2018. User's guide to correlation coefficients. Turk. J. Emerg. Med. 18: 91-93. [Medline] [CrossRef]

2. Akpinar, M. Y., Ozin, Y. O., Kaplan, M., Ates, I., Kalkan, I. H., Kilic, Z. M. Y., Yuksel, M. and Kayacetin, E. 2018. Platelet-to-lymphocyte ratio and neutrophil-to-lymphocyte ratio predict mucosal disease severity in ulcerative colitis. J. Med. Biochem. 37: 155-162. [Medline] [CrossRef]

3. Allenspach, K., Wieland, B., Gröne, A. and Gaschen, F. 2007. Chronic enteropathies in dogs: evaluation of risk factors for negative outcome. J. Vet. Intern. Med. 21: 700-708. [Medline] [CrossRef]

4. Bai, M., Xing, L., Feng, J., Huang, L., Li, J. and Liang, G. 2016. Mean platelet volume as a possible marker for monitoring the disease activity in ulcerative colitis. Int. J. Lab. Hematol. 38: e77-e79. [Medline] [CrossRef]

5. Bou Jaoude, J., Bakouny, Z., Hallit, R., Honein, K., Ghorra, C. and El Rassy, E. 2018. Platelet-to-lymphocyte and neutrophil-to-lymphocyte ratios in Crohn's disease: The controversy remains. Clin. Res. Hepatol. Gastroenterol. 42: e16-e18. [Medline] [CrossRef]

6. Craven, M. D. and Washabau, R. J. 2019. Comparative pathophysiology and management of protein-losing enteropathy. J. Vet. Intern. Med. 33: 383-402. [Medline] [CrossRef]

7. Craven, M., Simpson, J. W., Ridyard, A. E. and Chandler, M. L. 2004. Canine inflammatory bowel disease: retrospective analysis of diagnosis and outcome in 80 cases (1995-2002). J. Small Anim. Pract. 45: 336-342. [Medline] [CrossRef]

8. Dandrieux, J. R. S. 2016. Inflammatory bowel disease versus chronic enteropathy in dogs: are they one and the same? J. Small Anim. Pract. 57: 589-599. [Medline] [CrossRef]

9. Feng, J. R., Qiu, X., Wang, F., Chen, P. F., Gao, Q., Peng, Y. N., Lin, X., Liu, Q., Liu, J., Zhao, Q. and Li, J. 2017. Diagnostic value of neutrophil-tolymphocyte ratio and platelet-to-lymphocyte ratio in crohn's disease. Gastroenterol. Res. Pract. 2017: 3526460-3526465. [Medline] [CrossRef]

10. Gasparyan, A. Y., Ayvazyan, L., Mukanova, U., Yessirkepov, M. and Kitas, G. D. 2019. The platelet-to-lymphocyte ratio as an inflammatory marker in rheumatic diseases. Ann. Lab. Med. 39: 345-357. [Medline] [CrossRef]

11. Gianella, P., Lotti, U., Bellino, C., Bresciani, F., Cagnasso, A., Fracassi, F., D'angelo, A. and Pietra, M. 2017. Clinicopathologic and prognostic factors in short- and long-term surviving dogs with protein-losing enteropathy. Schweiz. Arch. Tierheilkd. 159: 163-169. [Medline] [CrossRef]

12. Goodwin, L. V., Goggs, R., Chan, D. L. and Allenspach, K. 2011. Hypercoagulability in dogs with protein-losing enteropathy. J. Vet. Intern. Med. 25: 273-277. [Medline] [CrossRef]

13. Heilmann, R. M., Berghoff, N., Mansell, J., Grützner, N., Parnell, N. K., Gurtner, C., Suchodolski, J. S. and Steiner, J. M. 2018. Association of fecal 
calprotectin concentrations with disease severity, response to treatment, and other biomarkers in dogs with chronic inflammatory enteropathies. $J$. Vet. Intern. Med. 32: 679-692. [Medline] [CrossRef]

14. Jacinto, A. M. L., Ridyard, A. E., Aroch, I., Watson, P. J., Morrison, L. R., Chandler, M. L. and Kuzi, S. 2017. Thromboembolism in dogs with protein-losing enteropathy with non-neoplastic chronic small intestinal disease. J. Am. Anim. Hosp. Assoc. 53: 185-192. [Medline] [CrossRef]

15. Jergens, A. E., Schreiner, C. A., Frank, D. E., Niyo, Y., Ahrens, F. E., Eckersall, P. D., Benson, T. J. and Evans, R. 2003. A scoring index for disease activity in canine inflammatory bowel disease. J. Vet. Intern. Med. 17: 291-297. [Medline] [CrossRef]

16. Jergens, A. E. and Simpson, K. W. 2012. Inflammatory bowel disease in veterinary medicine. Front. Biosci. (Elite Ed.) 4: 1404-1419. [Medline] [CrossRef]

17. Kapsoritakis, A. N., Koukourakis, M. I., Sfiridaki, A., Potamianos, S. P., Kosmadaki, M. G., Koutroubakis, I. E. and Kouroumalis, E. A. 2001. Mean platelet volume: a useful marker of inflammatory bowel disease activity. Am. J. Gastroenterol. 96: 776-781. [Medline] [CrossRef]

18. Keung, Y. K. and Owen, J. 2004. Iron deficiency and thrombosis: literature review. Clin. Appl. Thromb. Hemost. 10: 387-391. [Medline] [CrossRef]

19. Kılınçalp, S., Ekiz, F., Başar, O., Ayte, M. R., Coban, S., Yılmaz, B., Altınbaş, A., Başar, N., Aktaş, B., Tuna, Y., Erbiş, H., Uçar, E., Erarslan, E. and Yüksel, O. 2014. Mean platelet volume could be possible biomarker in early diagnosis and monitoring of gastric cancer. Platelets 25: $592-594$. [Medline] [CrossRef]

20. Korniluk, A., Koper-Lenkiewicz, O. M., Kamińska, J., Kemona, H. and Dymicka-Piekarska, V. 2019. Mean platelet volume (MPV): new perspectives for an old marker in the course and prognosis of inflammatory conditions. Mediators Inflamm. 2019: 9213074-14. [Medline] [CrossRef]

21. Kurtul, A. and Ornek, E. 2019. Platelet to lymphocyte ratio in cardiovascular diseases: a systematic review. Angiology 70: 802-818. [Medline] [CrossRef]

22. Li, B., Zhou, P., Liu, Y., Wei, H., Yang, X., Chen, T. and Xiao, J. 2018. Platelet-to-lymphocyte ratio in advanced cancer: review and meta-analysis. Clin. Chim. Acta 483: 48-56. [Medline] [CrossRef]

23. Liu, S., Ren, J., Han, G., Wang, G., Gu, G., Xia, Q. and Li, J. 2012. Mean platelet volume: a controversial marker of disease activity in Crohn's disease. Eur. J. Med. Res. 17: 27-7. [Medline] [CrossRef]

24. Marchetti, V., Lubas, G., Lombardo, A., Corazza, M., Guidi, G. and Cardini, G. 2010. Evaluation of erythrocytes, platelets, and serum iron profile in dogs with chronic enteropathy. Vet. Med. Int. 2010: 1-5. [Medline] [CrossRef]

25. Matowicka-Karna, J. 2016. Markers of inflammation, activation of blood platelets and coagulation disorders in inflammatory bowel diseases. Postepy Hig. Med. Dosw. 70: 305-312. [Medline] [CrossRef]

26. Matur, E., Ekiz, E. E., Erek, M., Ergen, E., Küçük, S. H., Erhan, S. and And Özcan, M. 2019. Relationship between anemia, iron deficiency, and platelet production in dogs. Med. Weter. 75: 6233-2019.

27. Mehain, S. O., Haines, J. M. and Lee, P. M. 2019. Platelet indices as biomarkers for characterization and determination of severity in canine chronic enteropathy. Vet. J. 248: 37-41. [Medline] [CrossRef]

28. Nakashima, K., Hiyoshi, S., Ohno, K., Uchida, K., Goto-Koshino, Y., Maeda, S., Mizutani, N., Takeuchi, A. and Tsujimoto, H. 2015. Prognostic factors in dogs with protein-losing enteropathy. Vet. J. 205: 28-32. [Medline] [CrossRef]

29. Öztürk, Z. A., Dag, M. S., Kuyumcu, M. E., Cam, H., Yesil, Y., Yilmaz, N., Aydinli, M., Kadayifci, A. and Kepekci, Y. 2013. Could platelet indices be new biomarkers for inflammatory bowel diseases? Eur. Rev. Med. Pharmacol. Sci. 17: 334-341. [Medline]

30. Patel, D., Trivedi, C. and Khan, N. 2018. Management of anemia in patients with inflammatory bowel disease (IBD). Curr. Treat. Options Gastroenterol. 16: 112-128. [Medline] [CrossRef]

31. Rejec, A., Butinar, J., Gawor, J. and Petelin, M. 2017. Evaluation of complete blood count indices (NLR, PLR, MPV/PLT, and PLCRi) in healthy dogs, dogs with periodontitis, and dogs with oropharyngeal tumors as potential biomarkers of systemic inflammatory response. J. Vet. Dent. 34: 231-240. [Medline] [CrossRef]

32. Ridgway, J., Jergens, A. E. and Niyo, Y. 2001. Possible causal association of idiopathic inflammatory bowel disease with thrombocytopenia in the dog. J. Am. Anim. Hosp. Assoc. 37: 65-74. [Medline] [CrossRef]

33. Senchenkova, E., Seifert, H. and Granger, D. N. 2015. Hypercoagulability and platelet abnormalities in inflammatory bowel disease. Semin. Thromb. Hemost. 41: 582-589. [Medline] [CrossRef]

34. Shabnam, I., D S, C. and B C, J. 2014. Ethylenediaminetetraacetic acid (EDTA)-dependent pseudothrombocytopenia: a case report. J. Clin. Diagn. Res. 8: FL03-FL04. [Medline]

35. Vaden, S. L. 2008. Protein-losing enteropathies, pp. 2007-2210. In: Small Animal Gastroenterology, 1st ed. (Steiner, J. M. ed.), Schluetersche, Hannover.

36. Voudoukis, E., Karmiris, K. and Koutroubakis, I. E. 2014. Multipotent role of platelets in inflammatory bowel diseases: a clinical approach. World J. Gastroenterol. 20: 3180-3190. [Medline] [CrossRef]

37. Washabau, R. J., Day, M. J., Willard, M. D., Hall, E. J., Jergens, A. E., Mansell, J., Minami, T., Bilzer T. W., WSAVA International Gastrointestinal Standardization Group. 2010. Endoscopic, biopsy, and histopathologic guidelines for the evaluation of gastrointestinal inflammation in companion animals. J. Vet. Intern. Med. 24: 10-26. [Medline] [CrossRef]

38. Yuce, Cure, M.C., Cure, E., Kiztanir, S. and Yazici, T. 2015. Evaluation of mean platelet volume before and after iron deficiency anemia treatment Sifa. Medical Journal 2: 7.

39. Yüksel, O., Helvaci, K., Başar, O., Köklü, S., Caner, S., Helvaci, N., Abayli, E. and Altiparmak, E. 2009. An overlooked indicator of disease activity in ulcerative colitis: mean platelet volume. Platelets 20: 277-281. [Medline] [CrossRef] 